\title{
METHOD OF CHARACTERISTICS FOR DYNAMIC GEOMETRICALLY NON-LINEAR ANALYSIS OF BEAMS
}

\author{
A.S. Shatnawi ${ }^{1 *}$, S.Z. Al-Sadder ${ }^{2}$, M.S. Abdel-Jaber ${ }^{1}$, R. A. Othman ${ }^{3}$ and N. S. Ahmed ${ }^{3}$ \\ ${ }^{1}$ Associate Professor, Department of Civil Engineering, The University of Jordan, Amman 11942, Jordan \\ ${ }^{2}$ Assistant Professor, Department of Civil Engineering, Hashemite University, Zarqa 13115, Jordan \\ ${ }^{3}$ Assistant Professor, Department of Civil Engineering, Baghdad University, Baghdad, Iraq \\ *(Corresponding author: E-mail: ashatnawi@ju.edu.jo)
}

Received: 14 January 2009; Revised: 30 October 2009; Accepted: 22 April 2010

\begin{abstract}
The large deflection of slender beams subjected to dynamic excitation is investigated in this paper. One-dimensional flexural vibration consisting of bending and shear waves is considered. A new formulation for the flexural wave behavior in geometrically non-linear beams is introduced. The formulation of the non-linear governing equations is established by considering elements under the effect of large-deflection and large-rotation while subjected to dynamic excitation. The governing equations are re-written in a numerical form using the method of characteristics. As representative examples, different types of support and load conditions are studied, e.g., cantilever and propped cantilever beams. The results showed that the method of characteristics with the proposed formulation is a suitable method to represent wave propagation phenomena in large deflection.
\end{abstract}

Keywords: Slender beam, large deflection; non-linear dynamics, method of characteristics

\section{INTRODUCTION}

Behavior of structural members could be assumed as linear behavior when material and geometrical changes due to applied external loads are small. Usually the change in material property is due to the change in the modulus of elasticity, while the change in geometry might be due to a change in cross-sectional area or length. When these changes are small, the linear system gives accurate results. However, there are many situations such as severe earthquake motion with vertical or horizontal components (or both), suspension beams or bridges of large spans subjected to pulse, wind or any dynamic loading, in which linear models will not yield acceptable results.

The most common methods of analysis of structural dynamics are based on finite element techniques [1,2] or on analytical solutions of the equations of motion [3-5]. Analytical methods are difficult to be obtained for structures with many degrees of freedom or when coupled action exists between axial and flexural waves. In addition, they are not usually formulated in a manner that makes it easy to simulate high frequency wave action within the individual structural members. A number of existing studies oriented towards the large deflection and/or wave propagation are observed $[6,7]$.

There is an obvious advantage in having a single method of analysis capable of simulating all types of dynamic behavior, whether gradual (slow) to more rapid or transient. Such a method is the Method of Characteristics (MOC) [8-12] that is considered herein and is shown to be capable of simulating static as well as dynamic problems. The popularity of the method comes from three of its attributes:

1.The possibility to reduce the partial differential equations to straightforward ordinary differential equations.

2.The mathematics of MOC underlines the essential physical wave behavior, as the associated characteristics directions are the time-space paths of information flow in the physical system. 
3.The computer resources required are relatively small, thus enabling highly complex structures to be simulated.

In the theoretical analysis of dynamic elasticity, MOC has received limited attention. Recently only serious attempts have been made to study the problem of elastic waves propagation by MOC. It was first applied by Pfgiffe [8] who obtained a general solution of the Timoshenko beam equations. Plass [9] extended the numerical method to involve beams with two different wave speeds. Subsequently, Chou and Mortimer [10] solved the same problem using MOC. They also carried out numerical integration for the special case where the shear and bending wave speeds are equal.

MOC was also applied by Chou and Koening [11] to several spherical and cylindrical problems. Vardy and Chan [12] used the method to model waves in skeletal structures comprising prismatic members. They used this method with the presence of coupling between axial and flexural waves. Vardy and Al-Sarraj [13], presented detailed formulations and numerical applications for the use of MOC in predicting the dynamic behavior of linear one-dimensional members (beams). Al-Sarraj et al [14] and Al-Sadder et al. [15] applied MOC to problems of non-linear vibration of axially loaded bars and beams, respectively. Consequently, the large deflection problems of beams was studied in static case by using different methods of analysis. Haisler et al. [16] and Haisler and Stricklin [17] presented solution techniques which are applicable to the solution of the non-linear algebraic or differential equations characterizing geometrically non-linear behavior.

In the following mathematical formulation, equations of motion in Cartesian coordinates are obtained for each type of wave Consequently, material property relationships are differentiated with respect to time. This leads to pairs of partial differential equations relating a force and a velocity or a couple and an angular velocity. Each pair of equations is expressed in ordinary differential form using MOC and the explicit finite difference technique is used to obtain the solution by a process of time marching. The accuracy and stability of the numerical solution are evaluated and discussed.

In the present work, the large deflection problem of slender beams is studied in dynamic state. One-dimensional flexural vibration is considered and a new formulation for the flexural wave behavior in geometrically non-linear beams is introduced by using MOC, and the numerical solution of the new equations is done by using the finite difference techniques.

\section{FORMULATION OF THE PROBLEM}

A small element of a beam of constant flexural rigidity $E I$ and actual length $d s$ with cross-section area, $A$, is considered as shown in Figure 1.

For simplifying, the following notations are defined as:

$M$ : bending moment

$V$ : lateral force

$\lambda$ : lateral velocity

$\psi:$ angular velocity

$\rho:$ density of the material

$A$ : area of cross section

$F$ : axial force

$Q$ : shear force

I: second moment of area

$E$ : modulus of elasticity 


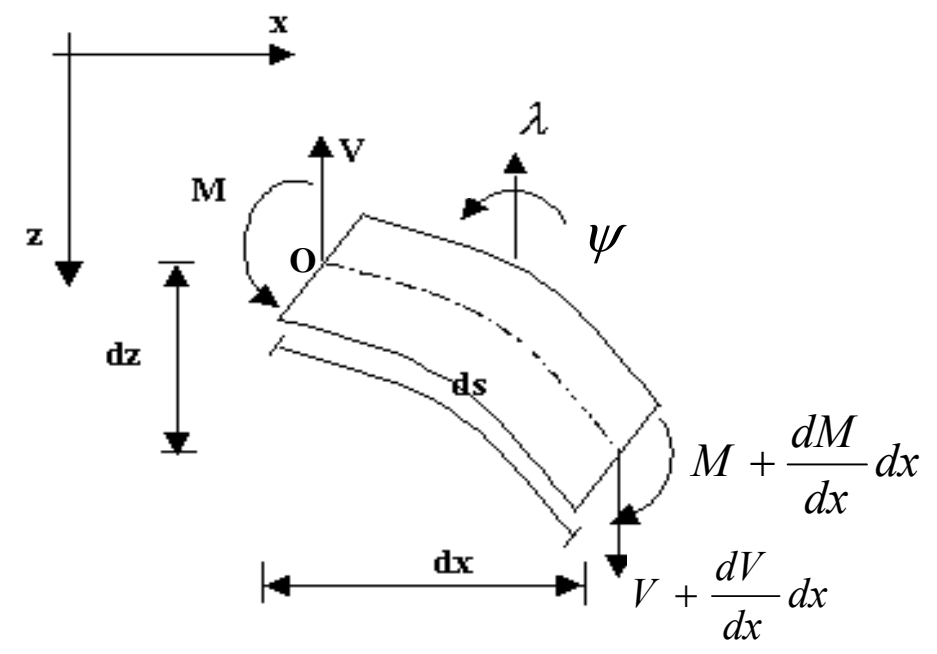

Figure 1. Small Beam Increment under Large Deflection.

Now, according to Newton's second law and applying dynamic equilibrium of forces in vertical direction, gives:

$-V+V+\frac{d V}{d x} d x=\rho A d s \frac{\partial \lambda}{\partial t}$

Where the right side of Eq. 1 represents the mass multiplied by acceleration.

Simplifying Eq. 1 yields

$\frac{d V}{d x}=\rho A \frac{\partial \lambda}{\partial t} \frac{d s}{d x}$

Then, from Figure 2, the relations between the two components and the original lateral force can be obtained as:

$V=Q \cos \theta+F \sin \theta$

$Q \sin \theta=F \cos \theta$

By substituting Eq. 4 into Eq. 3, one may obtain the following:

$$
V=\frac{Q}{\cos \theta}
$$

By differentiating Eq. 5 with respect to " $x$ " along with substituting $\cos \theta=\frac{d x}{d s} \quad$ (as shown in Figure 2), one may obtain the following:

$$
\frac{d V}{d x}=Q \frac{d^{2} s}{d x^{2}}+\frac{d Q}{d x} \frac{d s}{d x}
$$




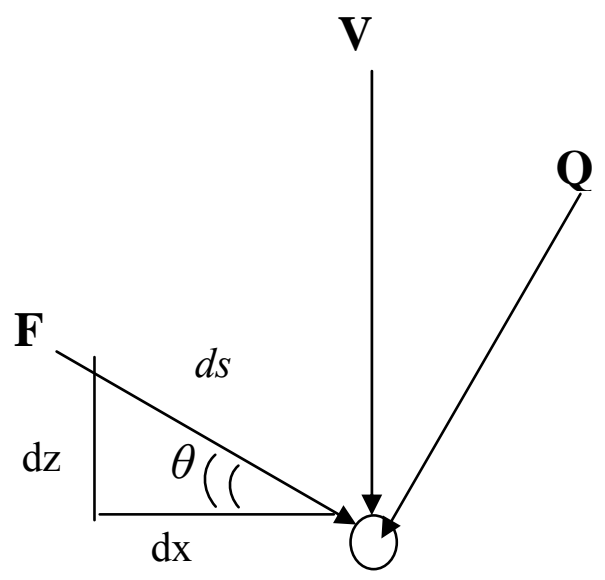

Figure 2. Relations Between Forces' Components.

Substituting Eq. 6 in Eq. 2 to get

$Q \frac{d^{2} s}{d x^{2}}+\frac{d Q}{d x} \frac{d s}{d x}=\rho A \frac{d \lambda}{d t} \frac{d s}{d x}$

$\frac{d Q}{d x}+Q \frac{d^{2} s}{d x^{2}} \frac{d x}{d s}=\rho A \frac{d \lambda}{d t}$

Similarly, applying dynamic equilibrium of moment about point $\mathrm{O}$ shown in Figure 1 gives:

$-M+M+\frac{d M}{d x} d x+\left(V+\frac{d V}{d x} d x\right) d x=\rho I d s \frac{d \psi}{d t}$

Where the right side of Eq. 9 represents the mass moment of inertia multiplied by the angular (rotational) acceleration which is expressed as the derivative of the angular velocity $(d \psi / d t)$.

Simplifying Eq. 9 yields

$\frac{d M}{d x}+V=\rho I \frac{d \psi}{d t} \frac{d s}{d x}$

Substituting Eq. 5 into Eq. 10 yields

$\frac{d M}{d x}+Q \frac{d s}{d x}=\rho I \frac{d \psi}{d t} \frac{d s}{d x}$

where

$$
\frac{d s}{d x}=\left[1+\left(\frac{d z}{d x}\right)^{2}\right]^{\frac{1}{2}}
$$

The material property relationships obtained from Hook's Law are differentiated with respect to time, $t$, to give the other two equations as follows [13]: 
- Shear:

$\frac{\partial Q}{\partial t}=K_{1} G A\left(\frac{\partial \lambda}{\partial x}-\psi\right)$

Moment:

$\frac{\partial M}{\partial t}=E I \frac{\partial \psi}{\partial x}$

Where, $K_{1}=$ Shear correction factor; $G=$ Shear modulus; and $\psi=$ Angular velocity

Eqs. 8, 13 and 11, 14 are pairs of hyperbolic partial differential equations where each of them may be expressed as an ordinary differential equation provided that their range of applicability is restricted to certain characteristic directions in the $x$ - $t$ plane [13]. In their characteristic form, the equations become as:

Shear along $\frac{d x}{d t}= \pm C_{S}$

$\frac{d Q}{d t} \pm C_{S} \rho A \frac{\partial \lambda}{\partial t}= \pm C_{S} Q \frac{d^{2} s}{d x^{2}} \frac{d x}{d s}-K_{1} G A \psi$

Moment along $\frac{d x}{d t}= \pm C$

$\frac{d M}{d t} \pm \rho I C \frac{d \psi}{d t} \frac{d s}{d x}= \pm C \frac{d s}{d x}$

where $C=\sqrt{\frac{E}{\rho}}$ and $C_{S}=\sqrt{\frac{K_{1} E}{\rho}}$ are speeds of transmission of moment and shear waves along member.

These equations can be integrated along the lines $L^{\prime} \mathrm{P} \& \mathrm{R}^{\prime} \mathrm{P}$ in the case of shear wave and LP \& RP in the case of bending wave as shown in Figure 3. Using central difference expressions yields:

- Shear:

$$
\begin{aligned}
& \left(Q_{P}-Q_{L}^{\prime}\right)-\rho A C_{S}\left(\lambda_{P}-\lambda_{L}^{\prime}\right)=-\rho A C_{S}\left(\frac{\psi_{p}+\psi_{L}^{\prime}}{2}\right) \Delta x-\frac{d^{2} s}{d x^{2}} \frac{d x}{d s}\left(\frac{Q_{P}+Q_{L}^{\prime}}{2}\right) \Delta x \\
& \left(Q_{P}-Q_{R}^{\prime}\right)+\rho A C_{S}\left(\lambda_{P}-\lambda_{R}^{\prime}\right)=-\rho A C_{S}\left(\frac{\psi_{p}+\psi_{R}^{\prime}}{2}\right) \Delta x+\frac{d^{2} s}{d x^{2}} \frac{d x}{d s}\left(\frac{Q_{P}+Q_{R}^{\prime}}{2}\right) \Delta x
\end{aligned}
$$

- Moment:

$$
\begin{aligned}
& \left(M_{P}-M_{L}\right)-\rho I C\left(\psi_{p}-\psi_{L}\right) \frac{d s}{d x}=-\left(\frac{Q_{P}+Q_{L}}{2}\right) \frac{d s}{d x} \Delta x \\
& \left(M_{P}-M_{R}\right)+\rho I C\left(\psi_{p}-\psi_{R}\right) \frac{d s}{d x}=+\left(\frac{Q_{P}+Q_{L}}{2}\right) \frac{d s}{d x} \Delta x
\end{aligned}
$$




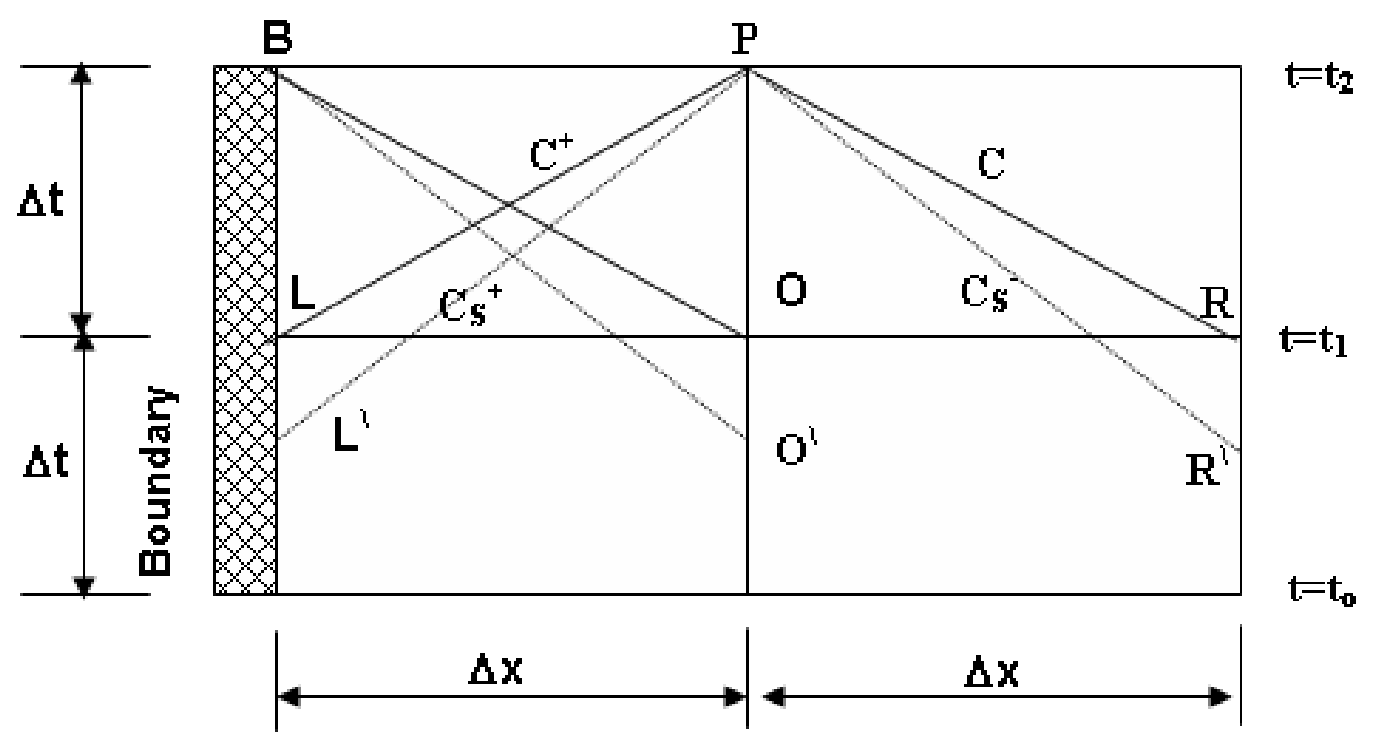

Figure 3. Numerical Characteristics Scheme.

\section{NUMERICAL EXAMPLES}

The non-linear dynamic governing equations that are represented by Eqs. 17 to 20 are solved simultaneously by a computer program using FORTRAN77 language. Several examples were carried out to evaluate the dynamic behavior of prismatic slender beams under large deflection. For all examples, the following numerical data of steel type prismatic and slender beam are used:

$\mathrm{L}=1 m, A=0.01 m^{2}, \mathrm{I}=8.333 \times 10^{-6} m^{4}, \mathrm{E}=200 \mathrm{GPa}, \rho=8000 \mathrm{~kg} / \mathrm{m}^{3}$

\subsection{Stability and Convergence of MOC}

The convergence of the MOC is usually tested using grid size dependence. Figures $4 \mathrm{a}$ and $4 \mathrm{~b}$ represent the nonlinear dynamic behavior for different number of grid lengths in a cantilever beam subjected to a constant applied tip moment. In linear analysis, 16-grid lengths are usually sufficient. Also, 16-grid lengths are sufficient for nonlinear axial and torsional waves [13 and 14]. The behavior of flexural waves is more complicated and hence a finer mesh is needed. However, Figures $4 \mathrm{a}$ and $4 \mathrm{~b}$ show that using 32-grid lengths are giving converging results and are giving sufficient accuracy when compared to the case of using 16-grid lengths. Using higher grid lengths will yield approximately same response obtained by using 32-grid lengths. For example, using 64-grid lengths produced results with slight difference in accuracy that is negligible, taking into consideration that the time required for performing analysis with 64-grid lengths was four times more than that needed using 32-grid lengths. Thus, the 32-grid lengths have been used in all numerical examples. However, the accuracy of solution obtained using MOC can be checked by comparison with results from other methods of solution.

Nonlinear dynamic response of a cantilever beam subjected to tip moment has been carried out using MOC and compared to results obtained by using MSC/NASTRAN [18], where finite element analysis is used. Figure 5 shows that the displacements at free end of a cantilever beam subjected to tip moment obtained by using MOC are slightly different than those obtained by using MSC/NASTRAN. A convergence criterion within MSC/NASTRAN proved that 10 elements for the beam under consideration gave sufficient accuracy where the nonlinear static finite element analysis was adopted. Large deflection option is chosen with Modified Newton-Raphson iterative solution of the non-linear equation. The slight difference between MOC and MSC/NASTRAN 
results is expected due to the different numerical approach adopted in the analysis. However, both methods yielded reasonable agreement. Precisely, In MOC, the displacement is calculated from the resulting velocity through approximate iterative numerical integration with different precisions and approach than those used in the case of using MSC/NASTRAN.

\subsection{Effect of Different Dynamic Loads}

Figures $6 \mathrm{a}$ and $6 \mathrm{~b}$ show a comparison between the behavior of a cantilever beam subjected to a suddenly applied constant bending moment at its free end for both large deflection dynamic behavior (i.e., non-linear) and small deflection dynamic behavior (i.e., linear). Figure 7a shows the bending moment at the fixed end for a propped cantilever beam under tip bending moment for both dynamic behaviors under large and small deflection. Figures $7 \mathrm{~b}$ to $7 \mathrm{~d}$ show the shear force at different locations for a propped cantilever beam subjected to a tip bending moment for both dynamic behaviors of large and small deflection.

Figures $8 \mathrm{a}$ and $8 \mathrm{~b}$ show the bending moment and shear force at the fixed end for a cantilever beam subjected to a tip vertical force. Results show that the shear force and bending moment-time history have similar shapes with magnified values in the case of large deflection.

In dynamic analysis, MOC is well suited to determine the fundamental natural frequencies of the structure by observing the repetitive pattern of the force or velocity response caused by the dynamic load as the frequency does not appear explicitly in MOC equations. Also by using Fast Fourier transform algorithm, high frequencies may be determined [13]. Natural frequencies could be obtained by any suitable method including analytical methods. However, in the present study, the natural frequencies of the structure were obtained by using the software MSC/NASTRAN [17] since it is used for comparison purposes. Then, these frequencies are used by suitable FORTRAN77 computer program to simulate the resonance condition.

Figure 9 shows the dynamic response of a propped cantilever beam subjected to a periodic load at its free end where the resonance occurred when the load frequency $\left(\omega_{\mathrm{p}}\right)$ matches the natural frequency of the beam $\left(\omega_{\mathrm{n}}\right)$.

Non-linear systems exhibit phenomena that cannot occur in linear systems. In this phenomenon, it can be seen that the amplitude of the vibration of the system has been found to increase or decrease as in the large deformation stage, the fundamental frequency is changed. This may have an important influence in resonance, as there will be a difference between the load and structure frequencies, i.e., canceling the resonance condition. When harmonic loading is applied with a frequency equal to the natural frequency of the beam, resonance will occur. The deflection in this case will increase with time leading to an increase in the member length and that will decrease the natural frequency of the beam. At a certain time the frequency of the loading is not matching with the natural frequency of the beam. The difference between them will be large enough to cause a jump in the vibration of the beam, as shown in Figure 10a. In addition, Figure 10b shows the change in the length of the beam that corresponds to the change in the response during the resonance case. One may keep in mind that jump phenomenon can not be observed in a linear analysis. 

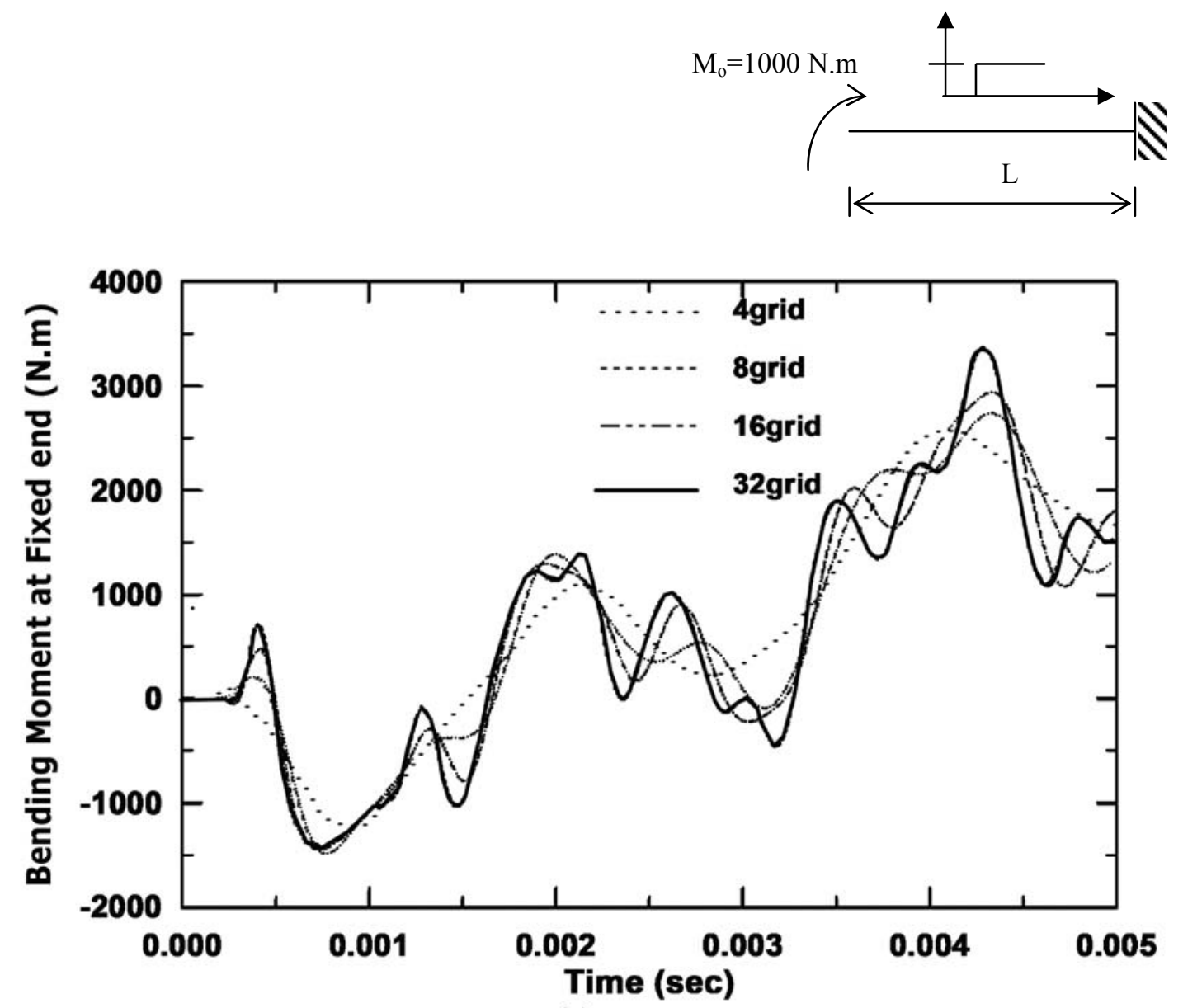

(a)

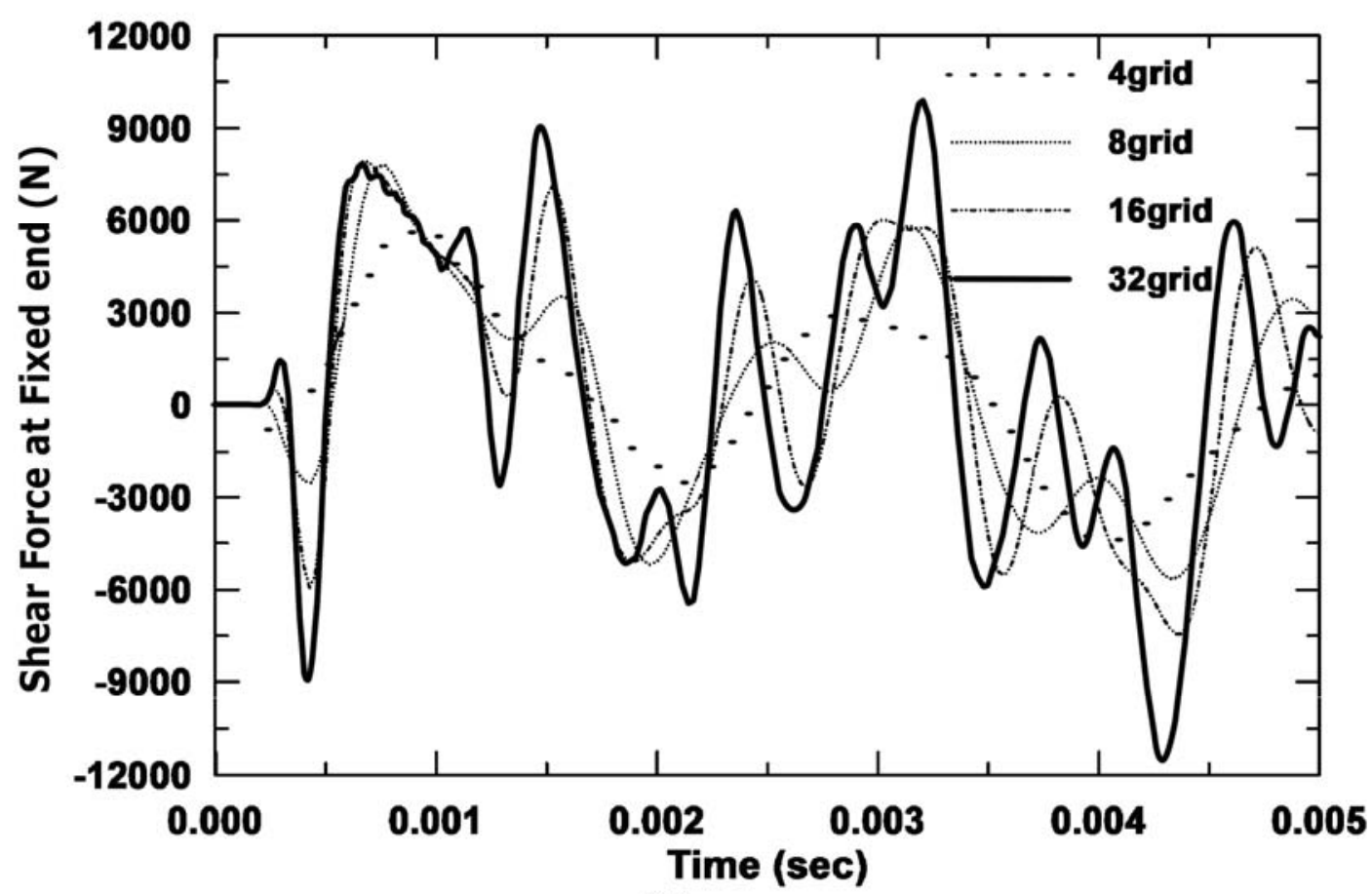

(b)

Figure 4. Grid Size Dependence for Large Deflection Dynamic Behavior. 

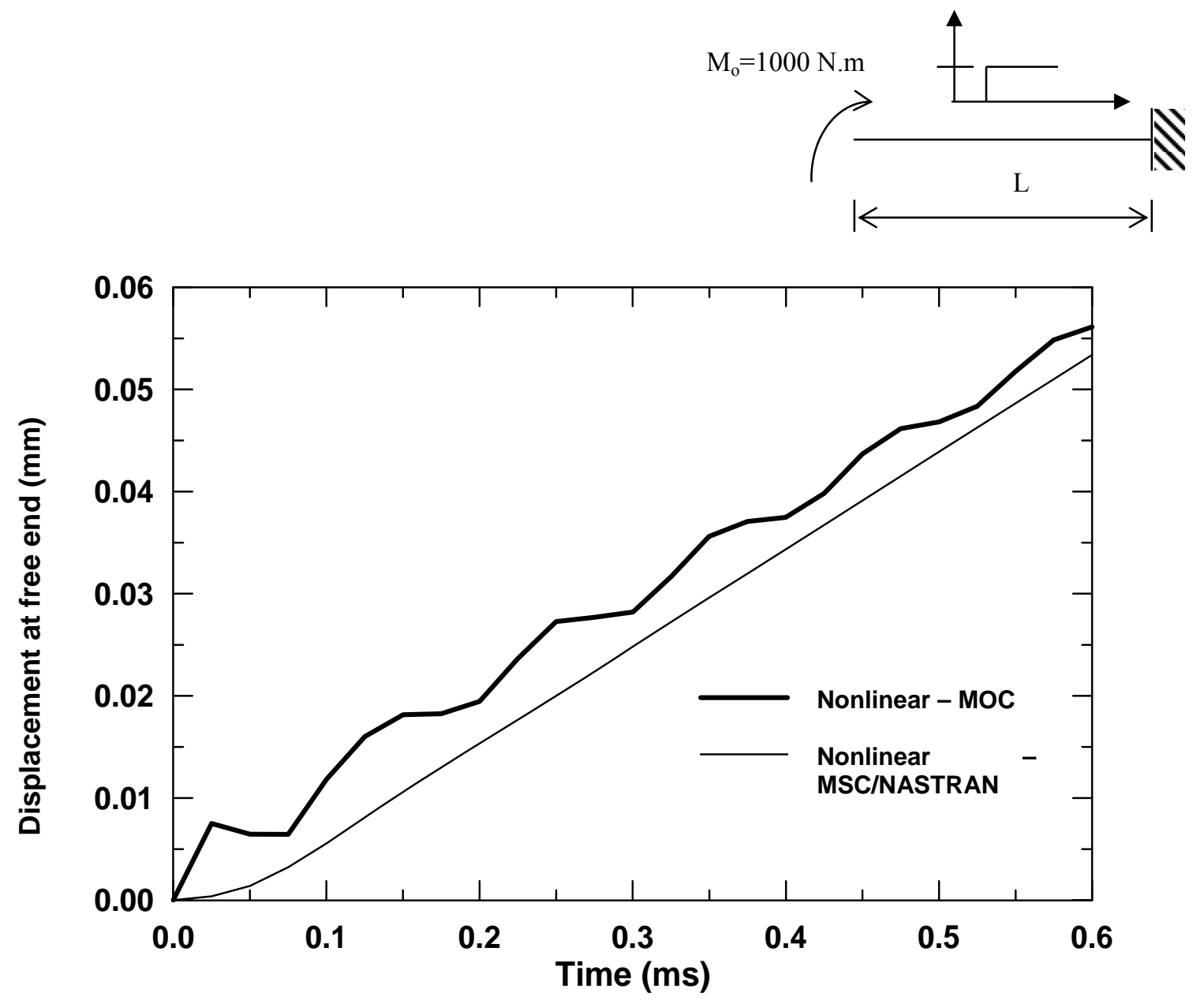

Figure 5. Comparison between MOC and MSC/NASTRAN for Nonlinear Dynamic Behavior of a Cantilever Beam subjected to Tip Moment. 

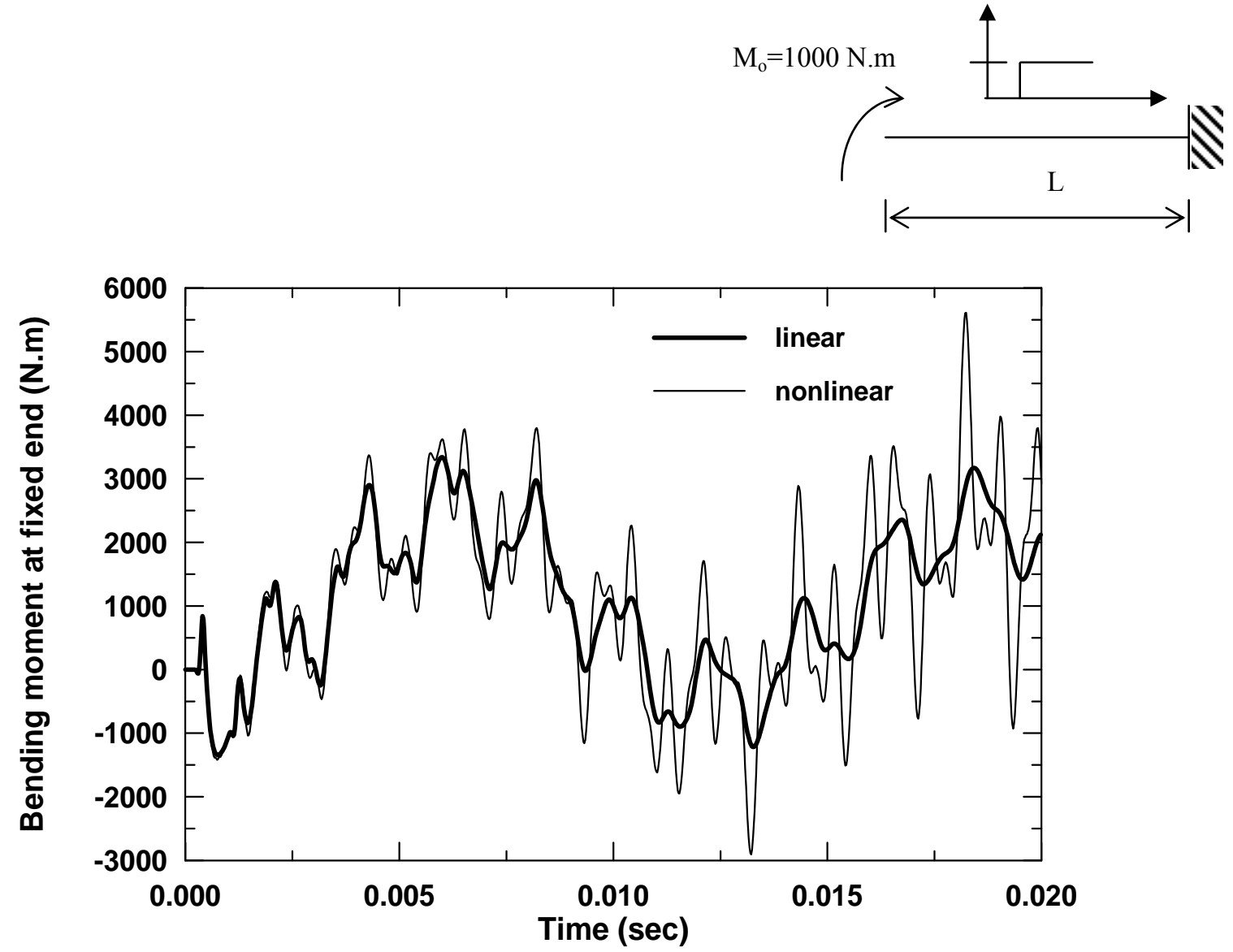

(a)

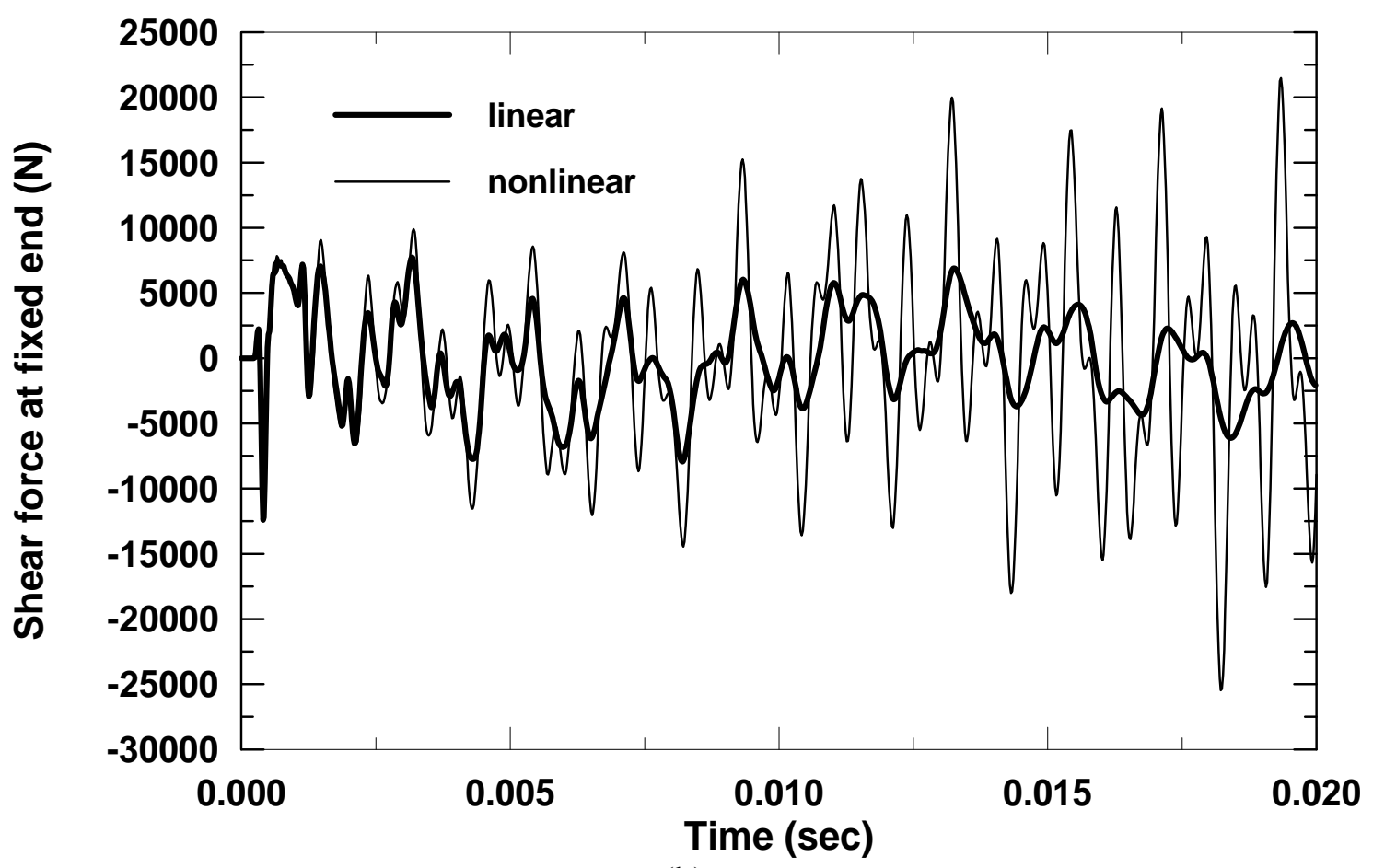

(b)

Figure 6. Comparison between Dynamic Responses under Large and Small Deflection for a Cantilever Beam under Tip Bending Moment. 


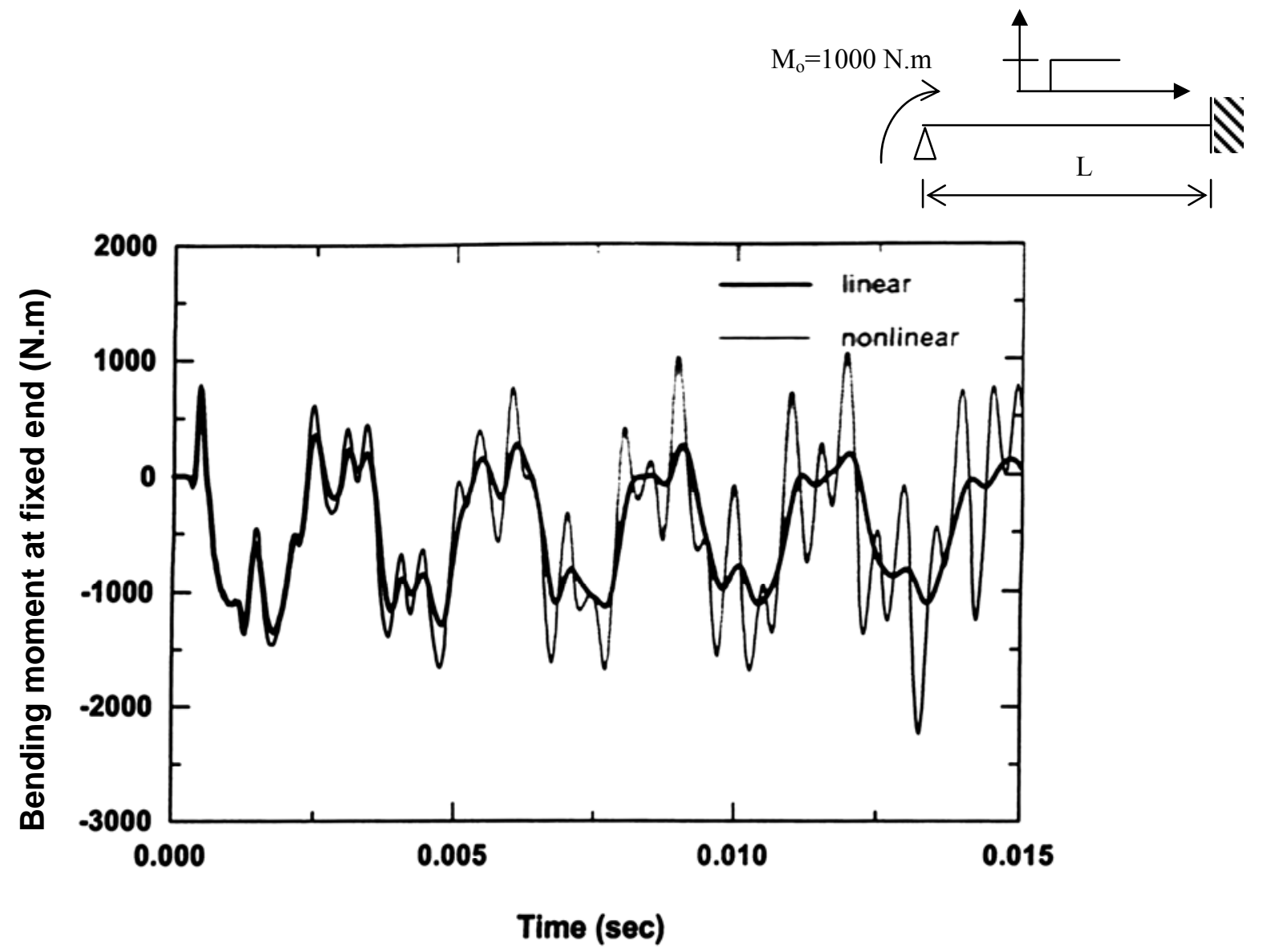

(7a)

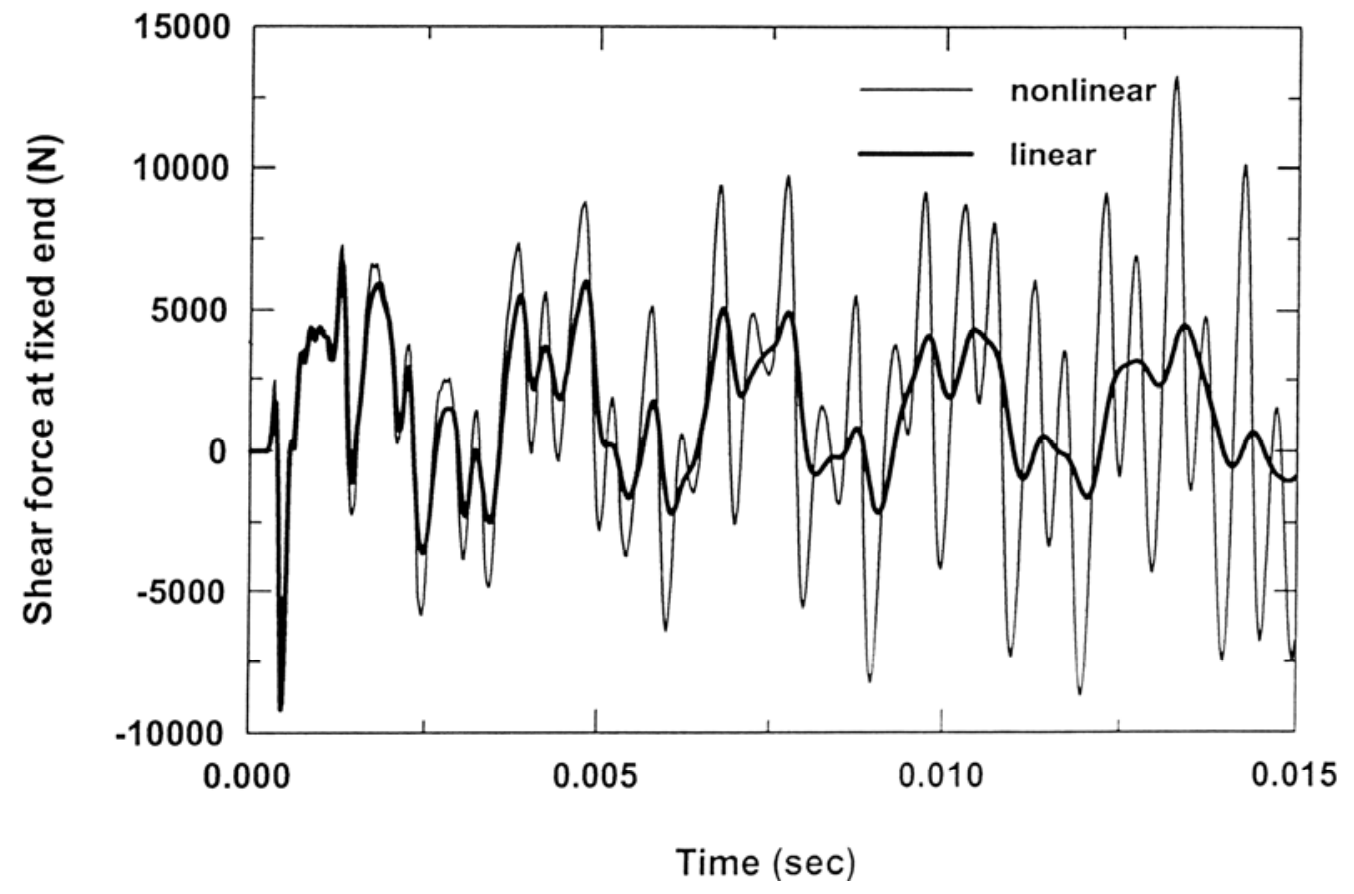

(7b)

Figure 7. Comparison between Dynamic Behaviors under Large and Small Deflection for a Propped Cantilever Beam under Tip Bending Moment. 


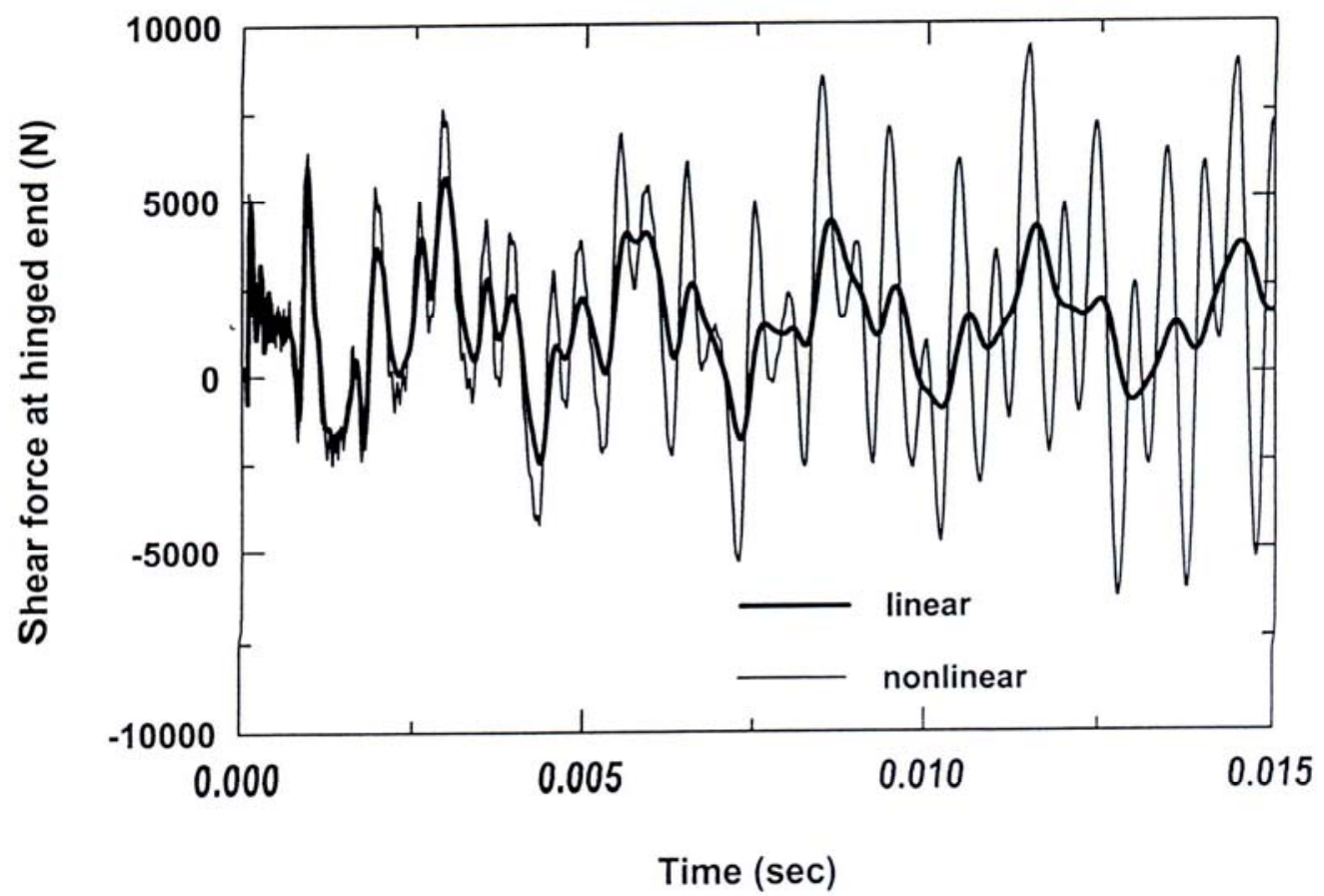

(7c)

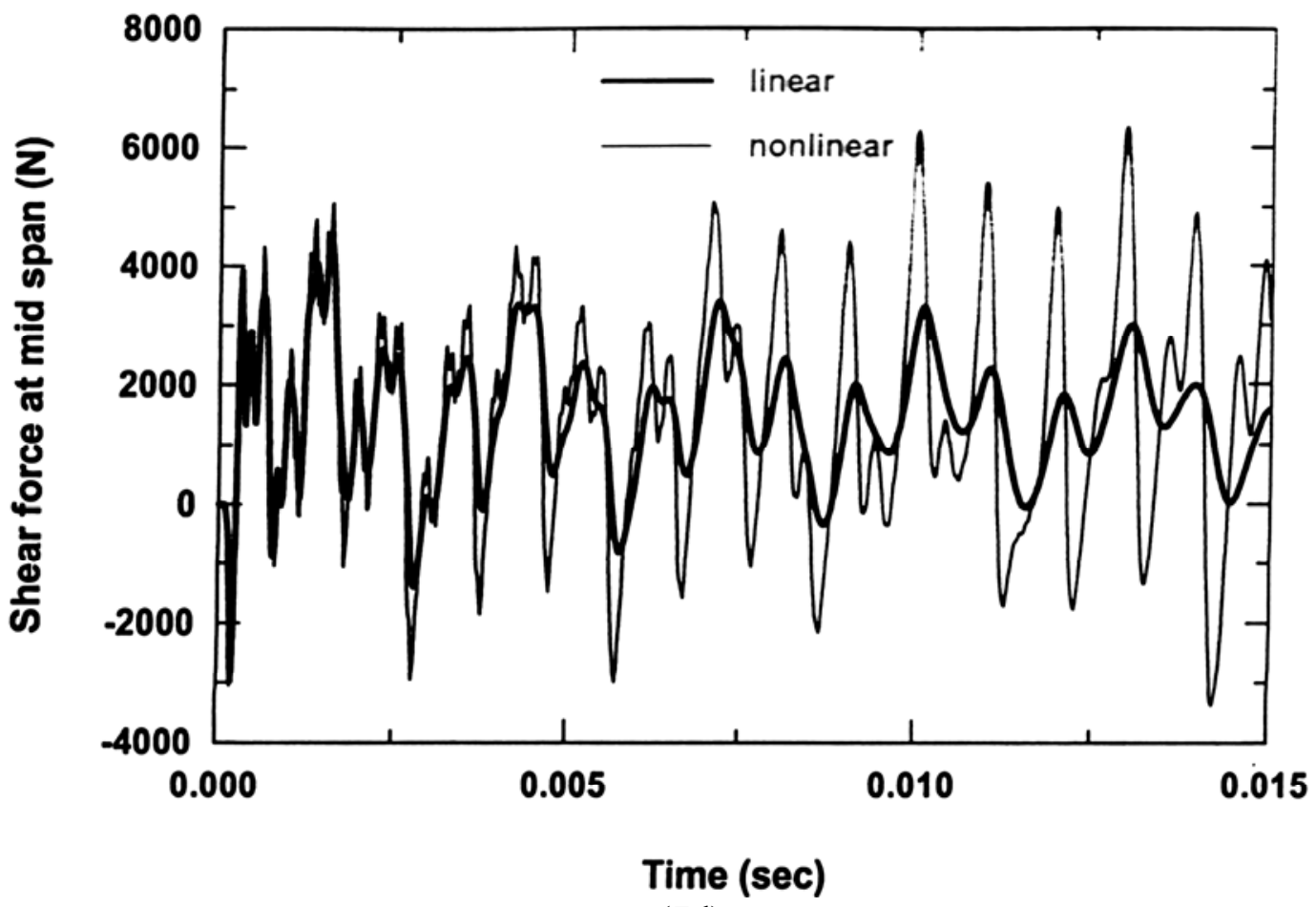

(7d)

Figure 7 Cont'd. 


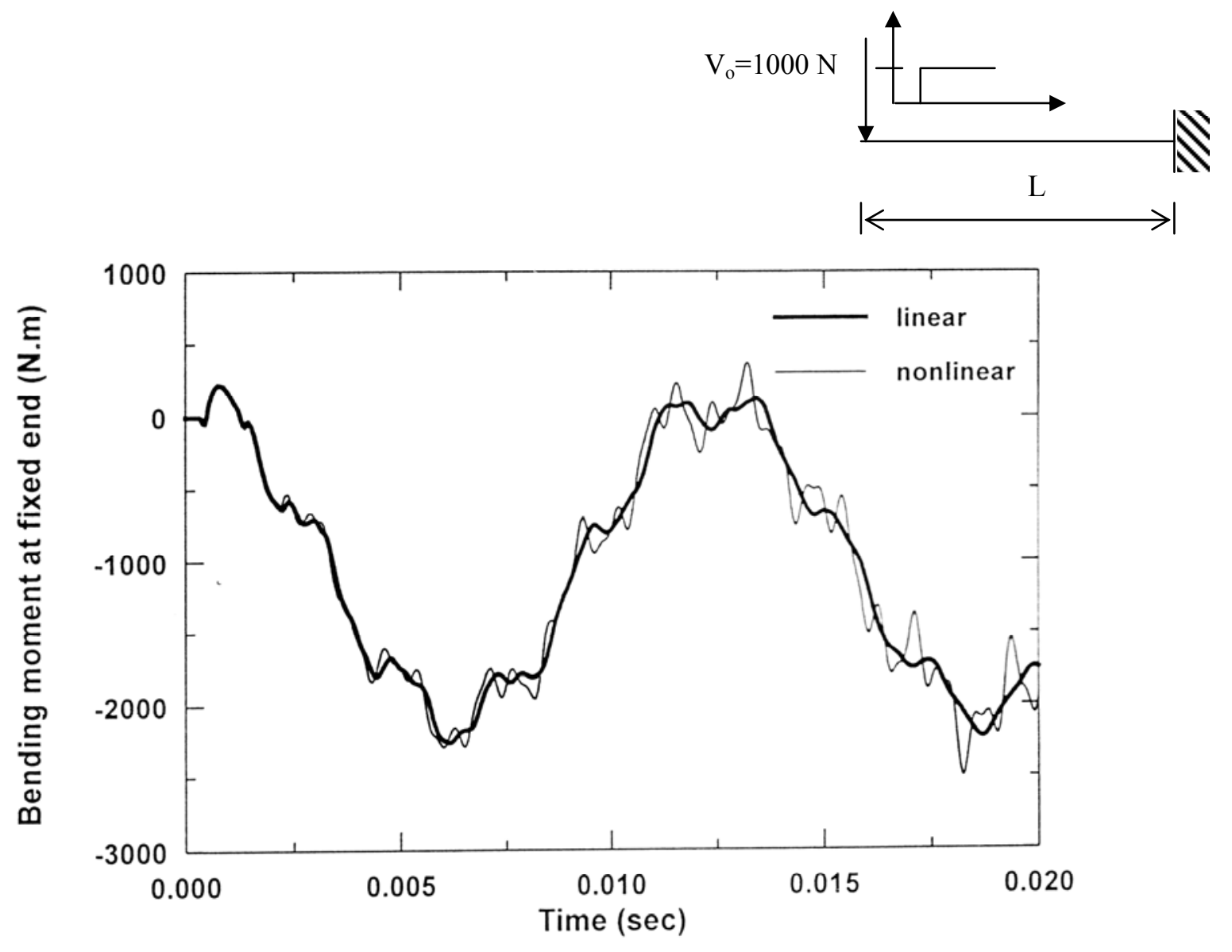

(a)

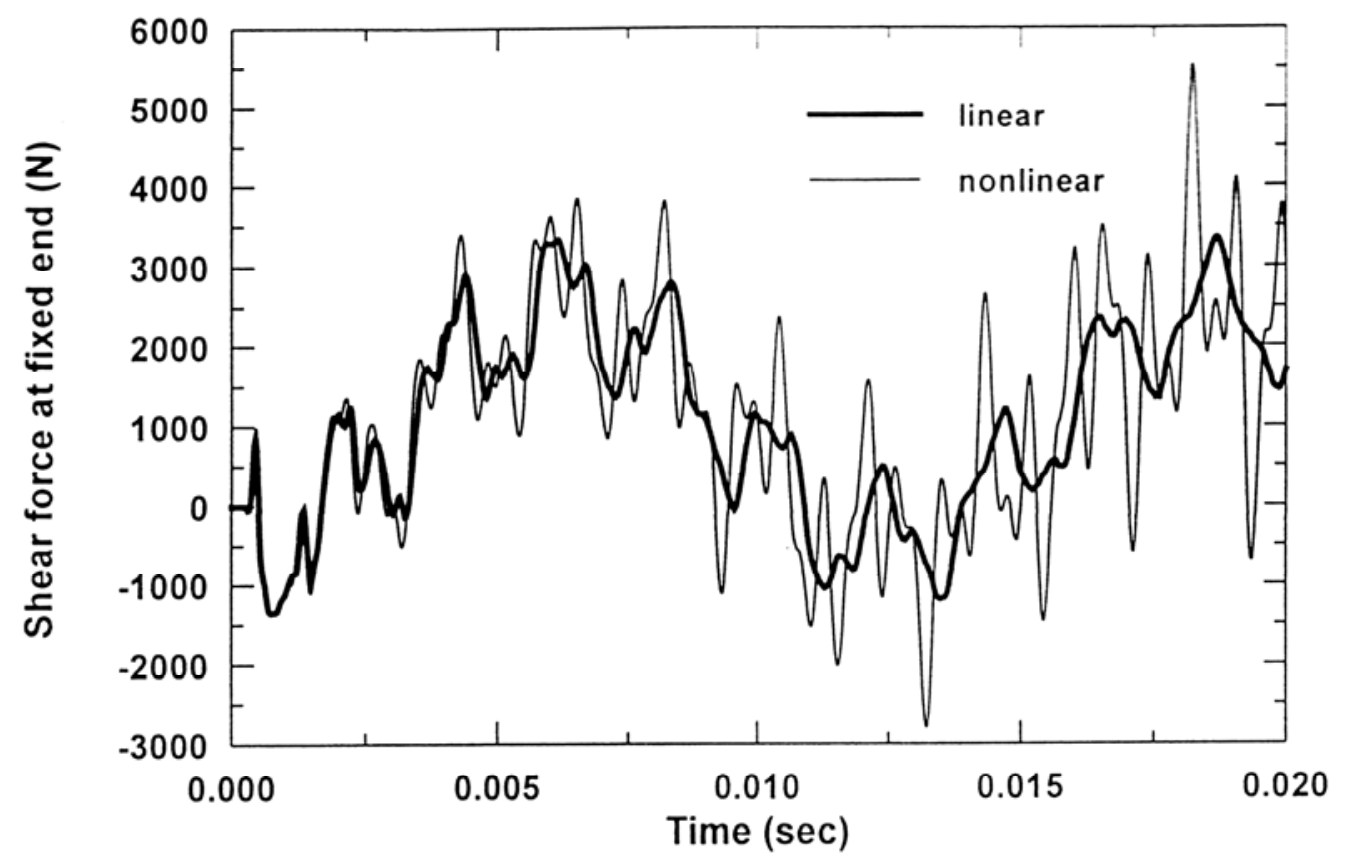

(b)

Figure 8. Comparison between Dynamic Behaviors under Large and Small Deflection for a Cantilever Beam under Tip Vertical Force. 


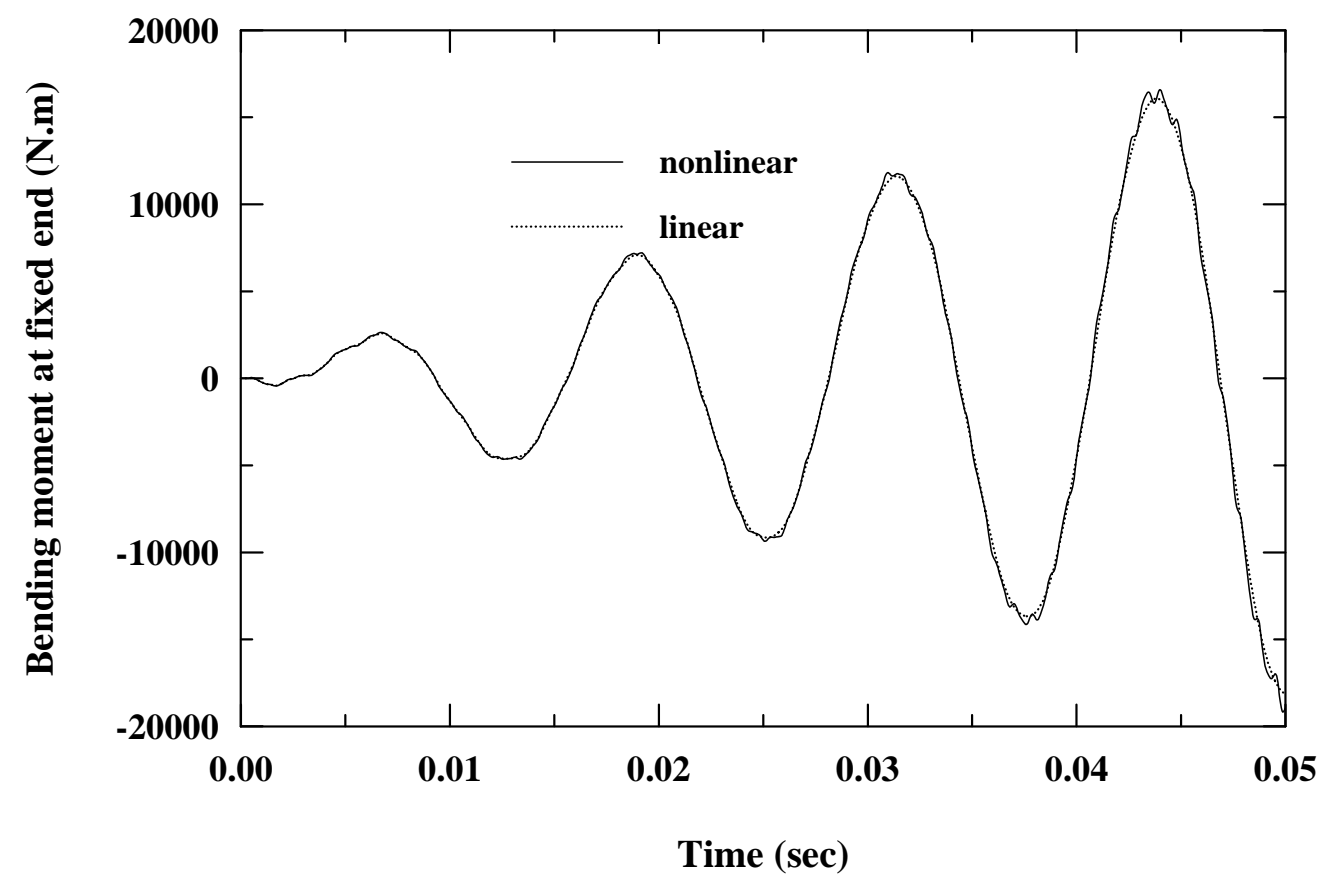

(a)

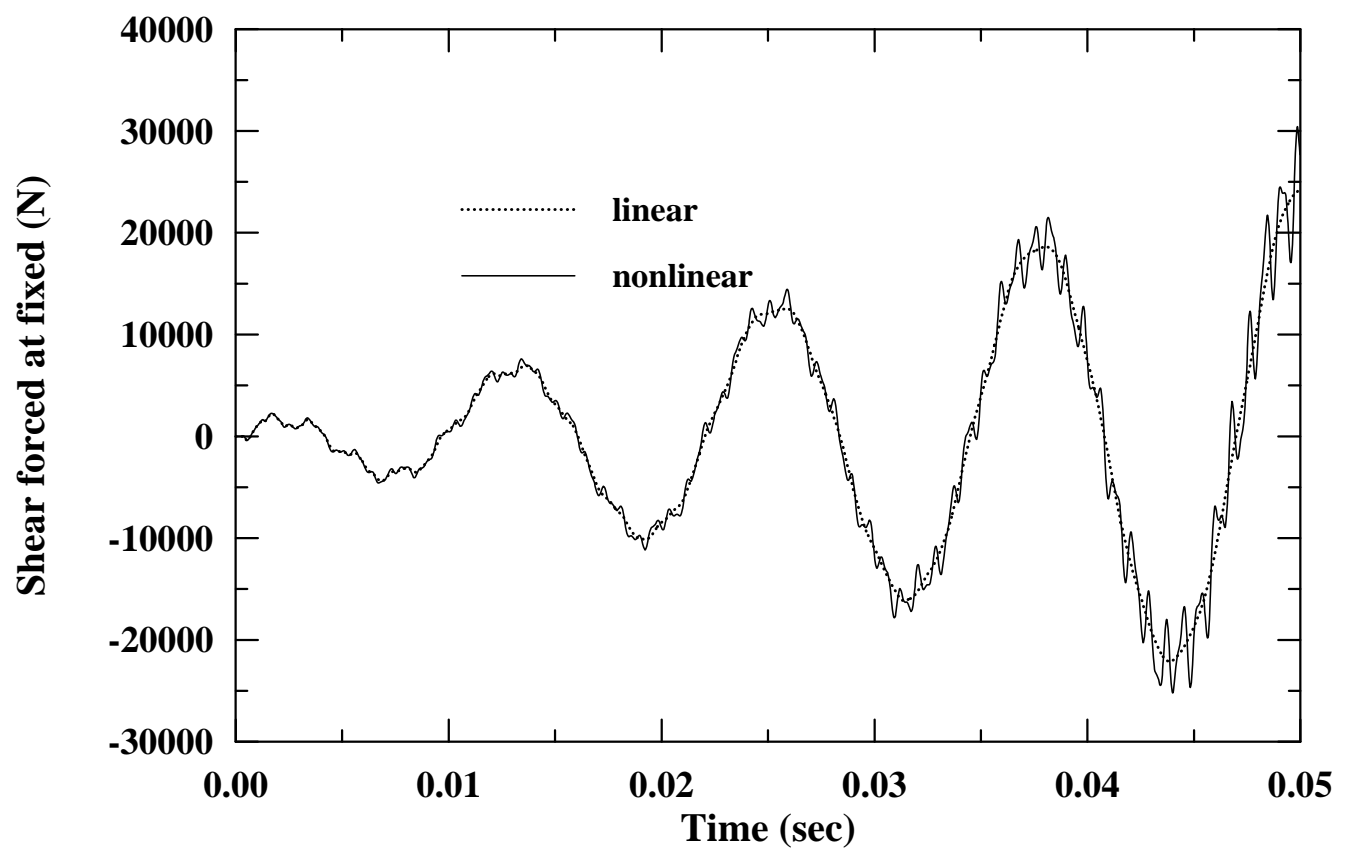

(b)

Figure 9. Resonance (i.e., $\omega_{\mathrm{p}}=\omega_{\mathrm{n}}$ ) for Linear and Nonlinear Cases. 

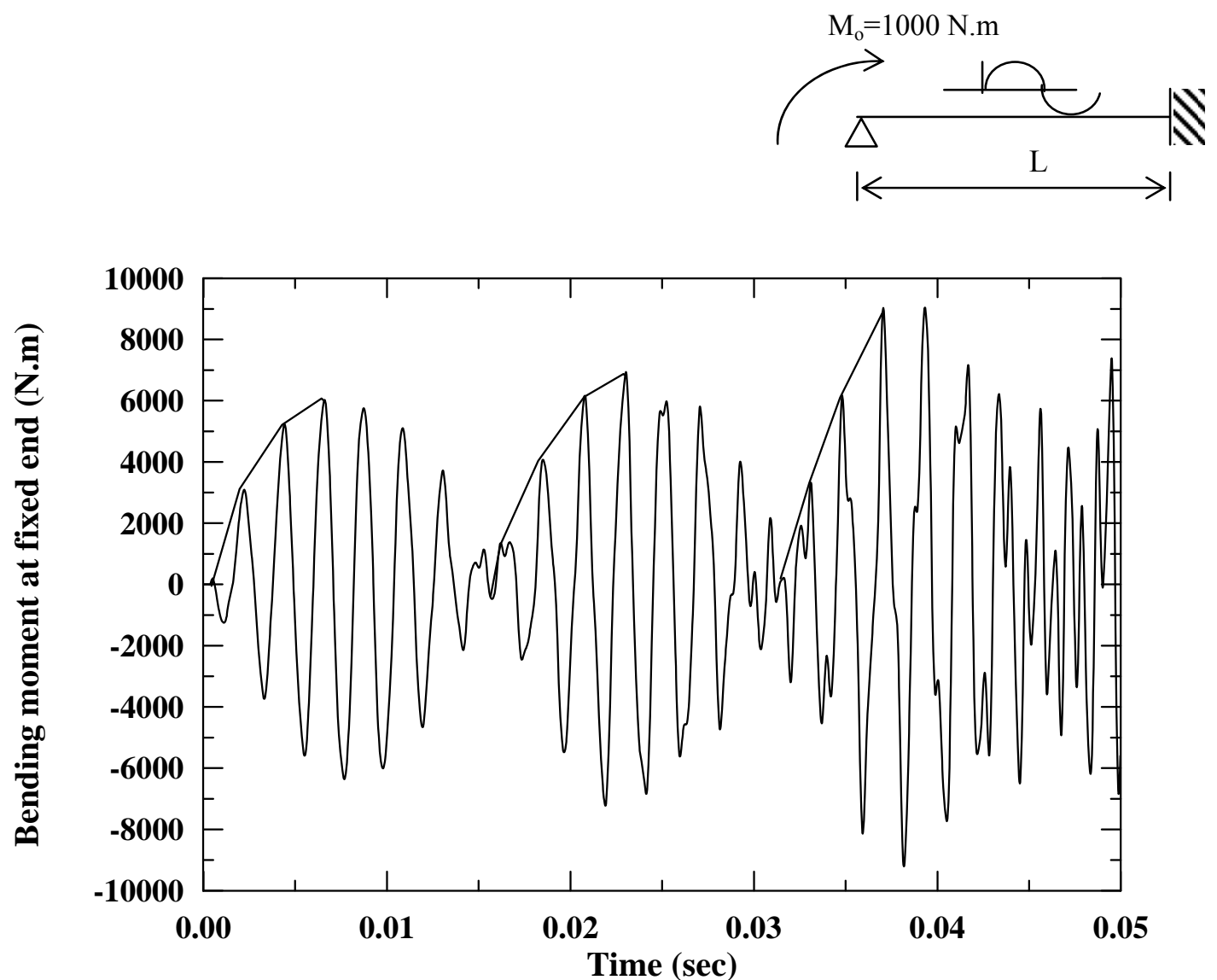

(a)

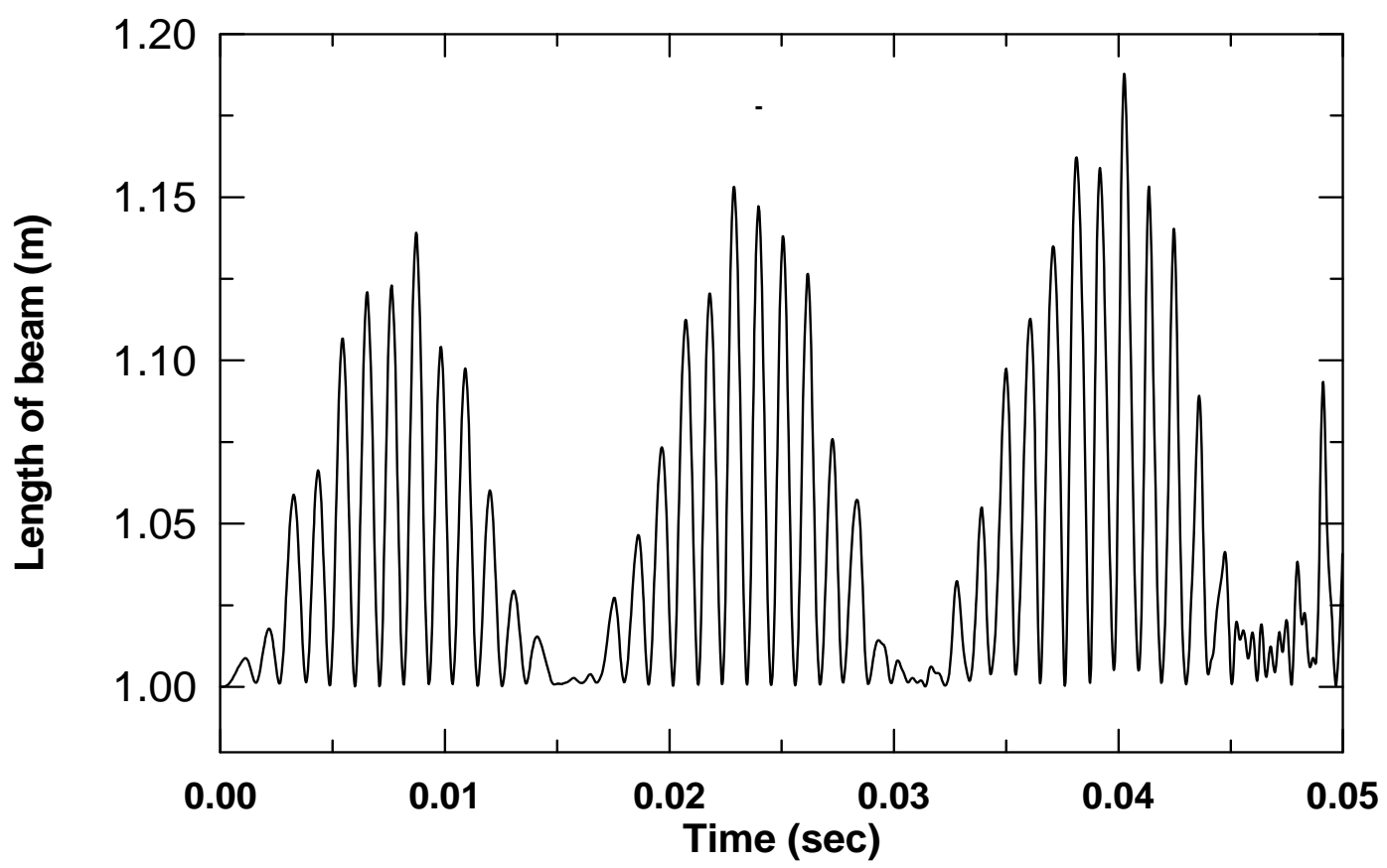

(b)

Figure 10. Jump Phenomena in Large Deflection at Resonance (i.e., $\omega_{\mathrm{p}}=\omega_{\mathrm{n}}$ ). 


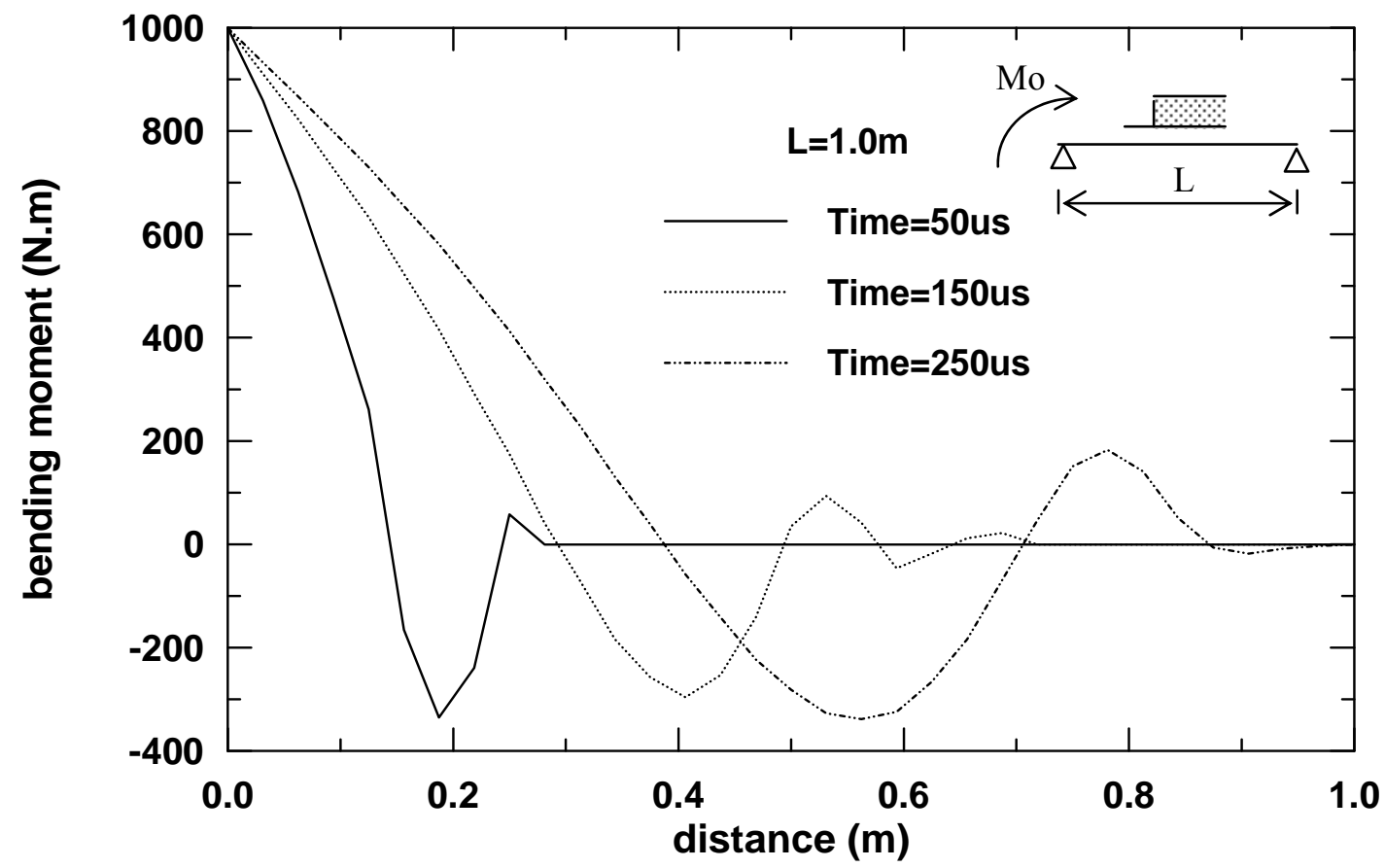

(11a)

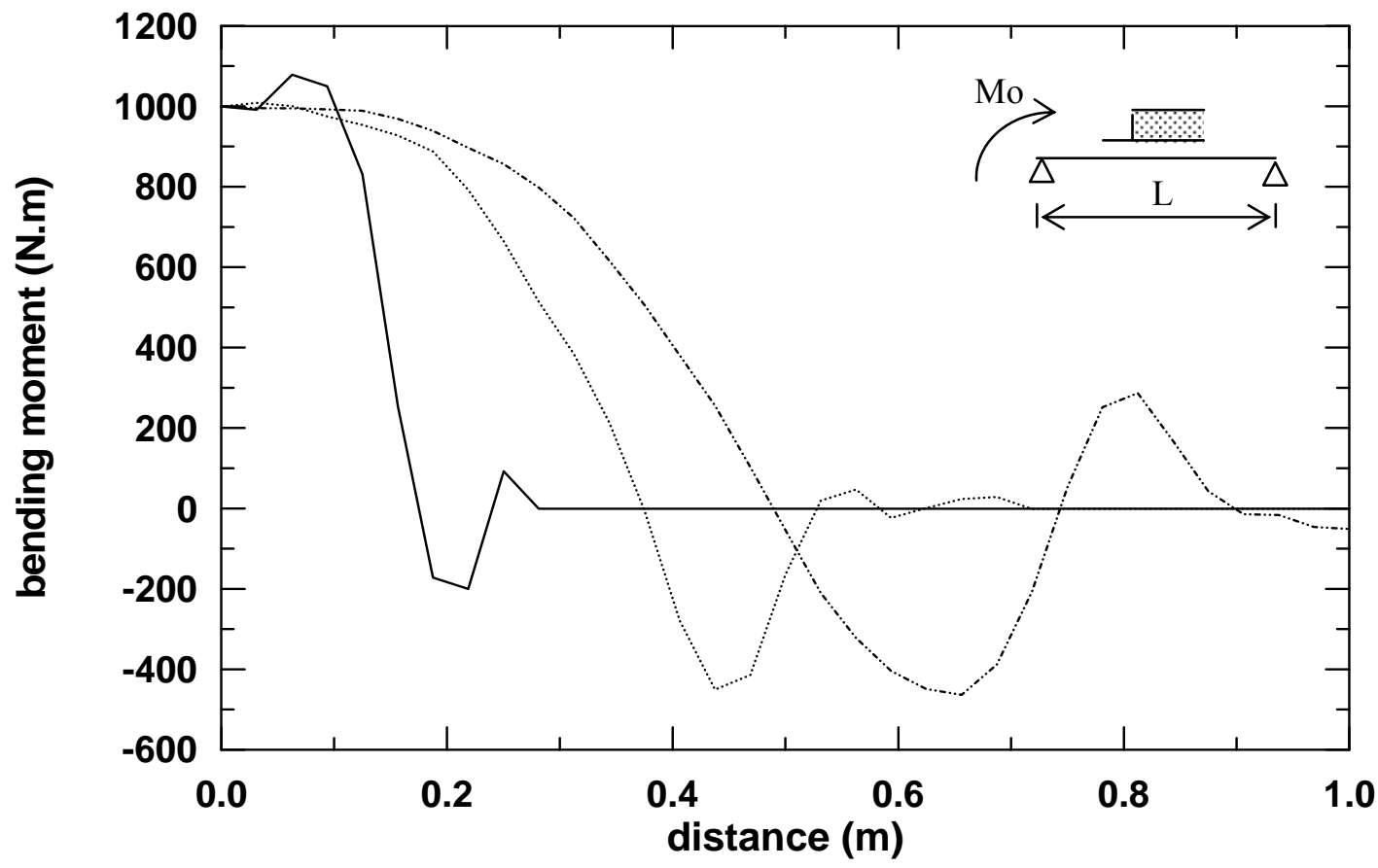

(11b)

Figure 11. Effect of Boundary Conditions on Wave Propagation. 

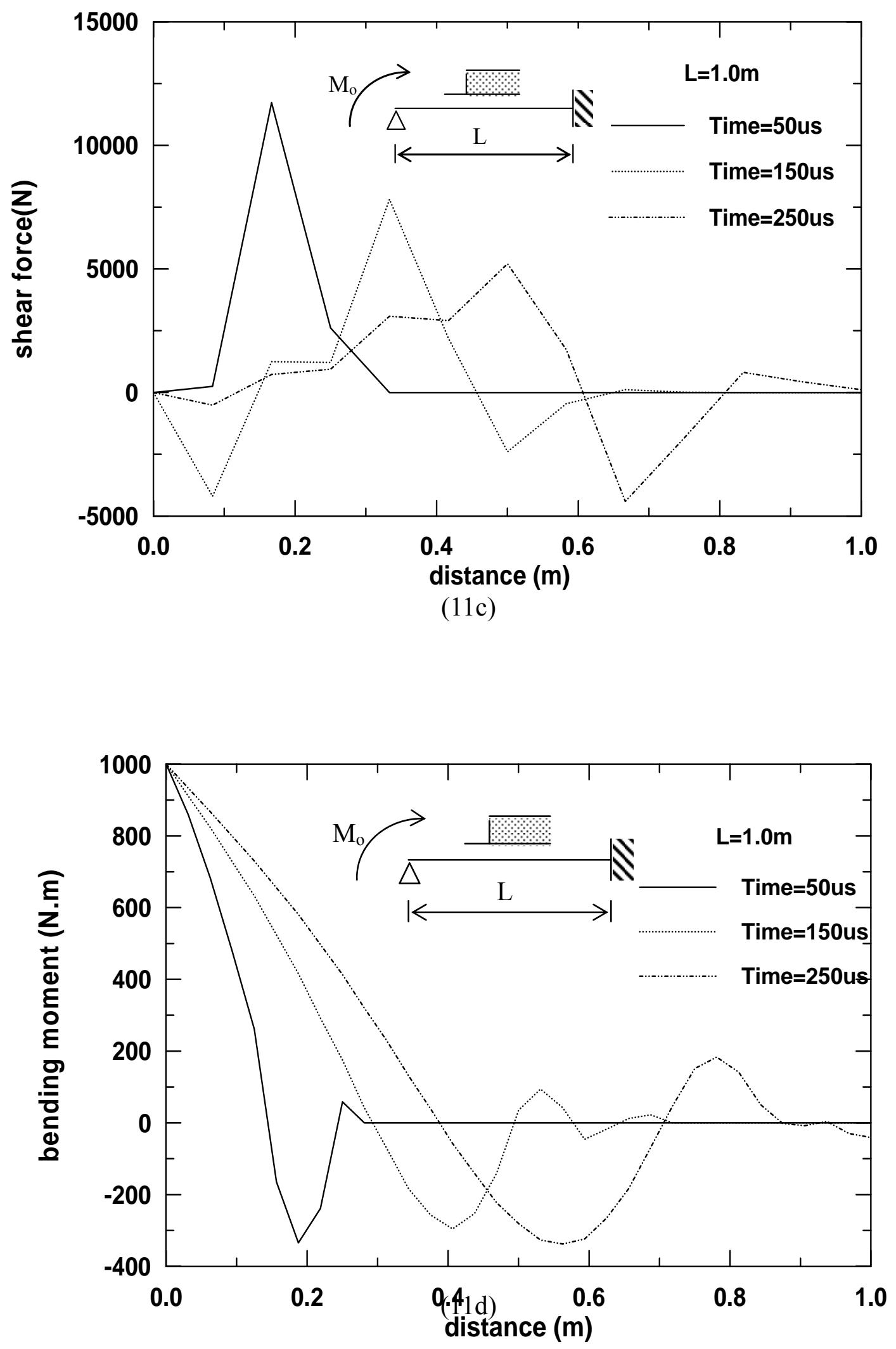

Figure 11. cont'd 

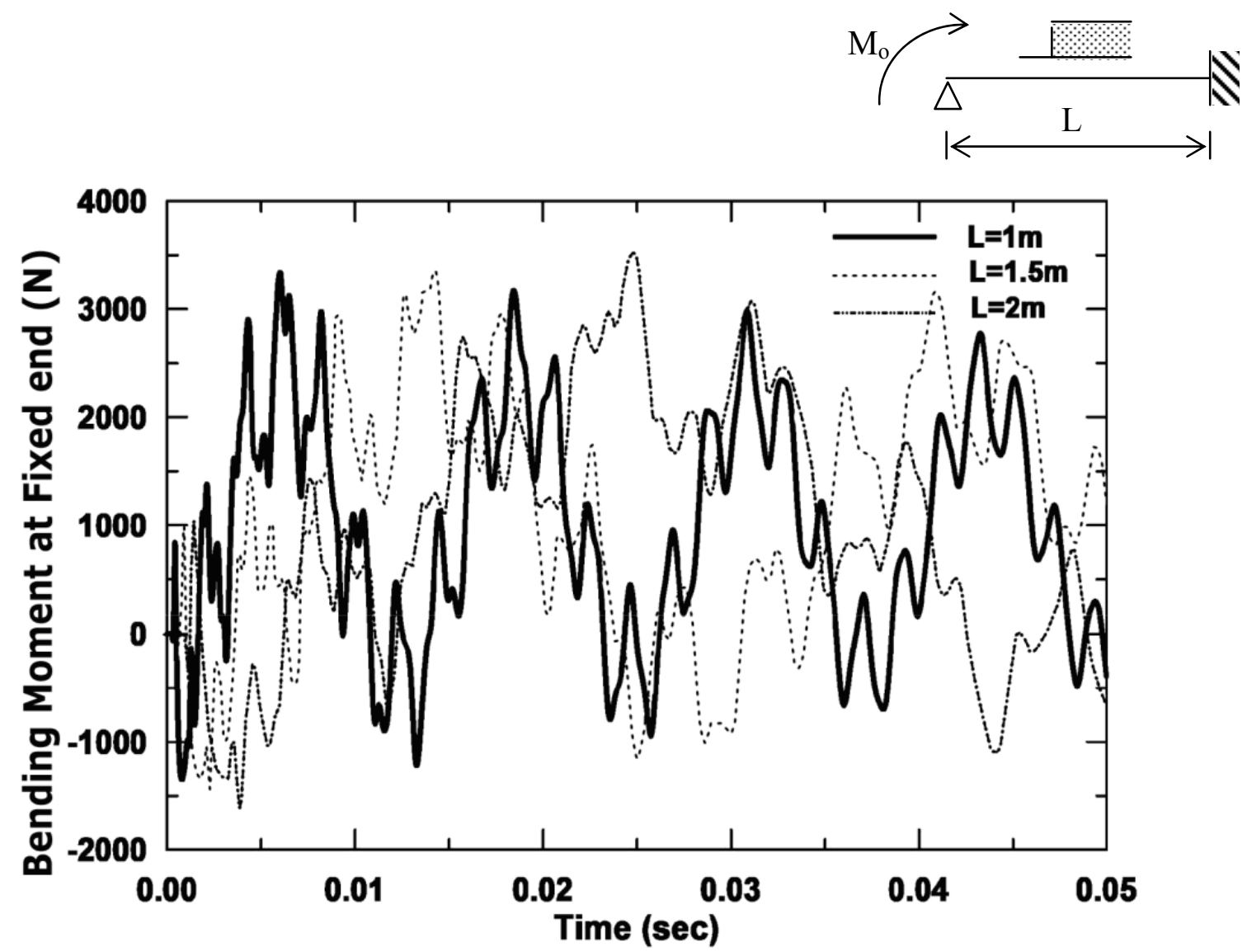

(12a)

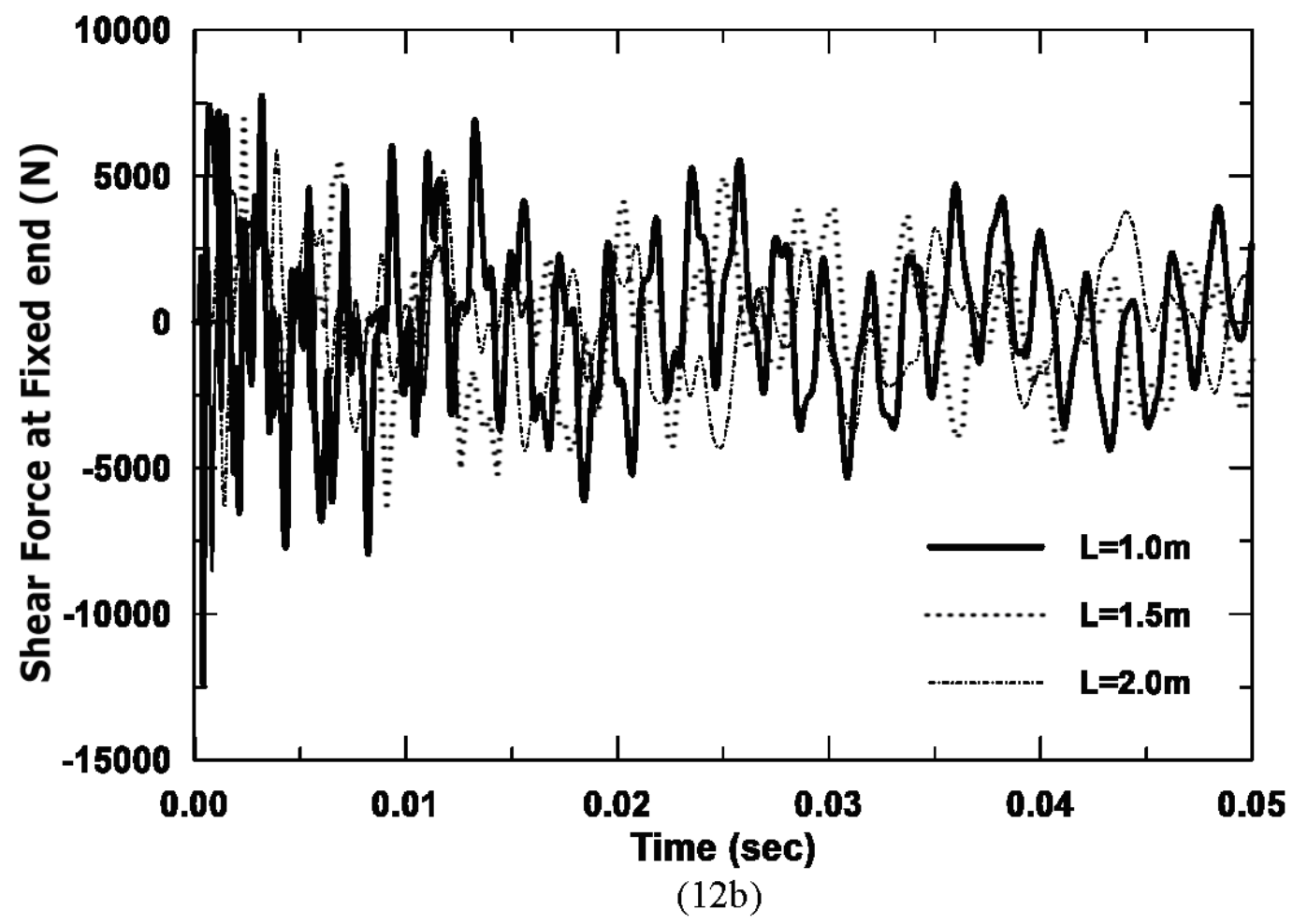

Figure 12. Effect of Beam Length on Wave Propagation 

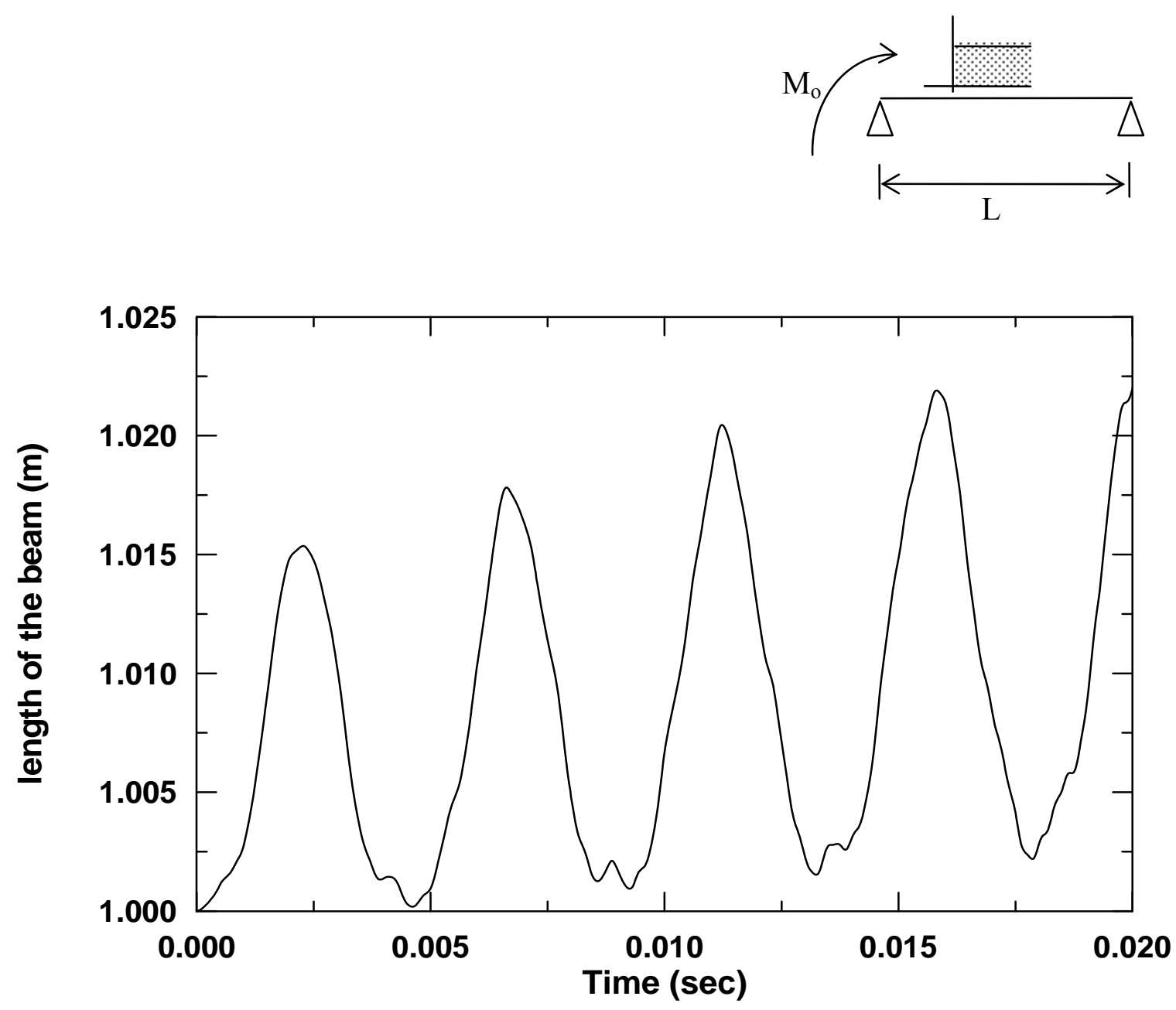

Figure 13. Actual Length of Beam during Vibration

\subsection{Effect of Boundary Conditions on Wave Propagation}

The propagation of bending waves in beams with different boundary conditions is illustrated in Figure 11. Figure 11a shows the bending moment variation of a simply supported beam subjected to a constant moment at one end. Consequently, Figures $11 \mathrm{~b}$ and $11 \mathrm{c}$ show bending and shear wave propagations in a cantilever subjected to a constant bending moment at its free end. Figure 11d explains how the waves are transmitted along a propped cantilever beam from the point of applied load to the rest of beam. The interaction of the applied waves that propagate through the beam length with those reflected at the fixed end, and the differences between the propagation speeds of the bending and shear waves cause significant changes in the shape of bending and shear waves as they travel throughout the beam. In addition, Figure 11 shows the dissipative nature of the flexural waves because of the difference between the bending and shear wave speeds.

\subsection{Effect of Beam Length on Wave Propagation}

Figure 12 shows the dynamic response of a cantilever beam subjected to constant applied moment at its free end with different lengths. It is observed that the waves travel in constant speed and when the length of beam is increased, the waves need more time to reach the boundary or any other point. Figure 12 explains the fact that when the length increases, the natural frequency will decrease. In 
linear analysis, the length of the member remains constant during the analysis and the change in length is assumed to be negligible. In the present procedure, a new length of the member is calculated every time step as shown in Figure 13. This leads to a change in natural period and in amplitude of vibration, thus producing nonlinear behavior of the member.

\section{CONCLUSIONS}

A new formulation for the flexural wave behavior in geometrically non-linear beams is introduced. The formulation of the non-linear governing equations is established by considering elements under the effect of large-deflection and large-rotation while subjected to dynamic excitation. The governing equations are re-written in a numerical form using MOC. Several conclusions can be summarized as:

\section{$\underline{\text { General Conclusions }}$}

- MOC can be used to simulate the linear and non-linear dynamic behavior of prismatic members subjected to any type of loading.

- The main advantage of MOC is that the non-linear equations are solved directly without the need for any iterative or incremental procedures.

- The interaction between shear and bending waves leads the flexural waves to propagate in prismatic members in a depressive (changed) form.

- MOC can efficiently predict forces, velocities and displacements throughout the member at any time increment.

- Equations describing the longitudinal transmission of stress waves along one-dimensional prismatic members can be expressed in a characteristic form and integrated by approximate finite difference methods.

- Unlike finite element methods, MOC takes proper account of wave motions along the members and so gives more realistic predictions of behavior at high frequencies.

\section{$\underline{\text { Specific Observations }}$}

- From analysis, convergence of behavior is achieved with 32 grid lengths along the member.

- The propagation of the flexural waves is not only dependent on the material properties but also on the sectional properties.

- The dynamic load factor is greater than (2) in flexural wave vibration.

- The fundamental frequency can be obtained by observing the repetitive pattern of the response. Also by using Fast Fourier transform algorithm, high frequencies can be determined.

- The non-linear large deflection time period and frequency of vibration are approximately equal to linear small deflection values.

- In the numerical integration it is important to carry out interpolations along the t-axis not along $\mathrm{x}$-axis.

- In linear (small-angle bending) dynamic vibration phenomenon can not be predicted but it can be predicted in non-linear (large-angle bending) dynamic vibration. 


\section{REFERENCES}

[1] Zienkiewicz, O.Z., "The Finite Element Method”, 3rd Edition. McGraw-Hill, 1977.

[2] Ross, C.T.F., "Finite Element Method in Structural Mechanic, 1st edition, Chichester Ellis Harwood, 1985.

[3] Clough, R.W. and Penzien, J., "Dynamics of Structures", NY : McGraw-Hill, 1975.

[4] Coates, R.C., Couiie, M.G. and Kong, F.K., "Structural Analysis", 2nd Edition, New York: Van Nostrand Reinhold, 1986.

[5] Johnson, D. “Advanced Structural Mechanics", London: Collins, 1986.

[6] Pany, C. and Rao, G.V., "Large Amplitude Free Vibrations of a Uniform Spring-Hinged Beam", Journal of Sound and Vibration, 2004, Vol. 271, pp. 1163-1169.

[7] Lande, R.H. and Langley, R.S., "The Energetics of Cylindrical Bending Waves in a Thin Plate", Journal of Sound and Vibration, 2005, Vol. 279, pp. 513-518.

[8] Pfgiffer, R., “über Die Differertialbeichung der Trasversalen Stabschwingunguen," Z Angew. Math. Mech., 1947, No. 3, pp. 25-27.

[9] Plass, H.I., "Some Solution of Timoshenko Beam Equation for Short Pulse-Type Loading," Journal of Applied Mechanics, 1958, Vol. 25, pp.379-385.

[10] Chou, P.C. and Mortimer, "Solution of One-dimensional Elastic Wave Problems by the (MOC)," J. of Applied Mechanics, ASME, 1967, Vol. 34, pp.745-750.

[11] Chou, P.C. and Koening, H.A., "A Unified Approach to Spherical Elastic Waves by the (MOC)," Journal of Applied Mechanics, Trans., ASME, 1966, Series 1, No. 88, pp.159-168.

[12] Vardy, A.E. and Chan, L.I., "Truss Analysis by Boundary Characteristics,” ASCE, Journal of Engineering Mechanics, 1988, Vol. 114, No. 3, pp. 520-535.

[13] Vardy, A.E. and Al-Sarraj, A.T. "Method of Characteristics Analysis of One-Dimensional Members", Journal of Sound and Vibration, 1989, Vol. 129, No. 3, pp. 479-487.

[14] Alsarraj, A.T., Othman, R.A. and Jwad, Z.M., "Non-linear Vibration of Axially Loaded Bars," Journal of Engineering and Technology, 1994, Vol. 12, No. 9, pp. 37-45.

[15] Al-Sadder, Samir, Othman, R., Shatnawi, Anis and Abdel-Jaber, M., "Dynamic Behavior of Slender Steel Beams under Large Deflection by the Method of Characteristics", $6{ }^{\text {th }}$ Int. Conference on Steel and Aluminum Structural Engineering, ICSAS'07, 2007.

[16] Haisler, W.E., Stricklin, J.A. and Stebbins, F.J., "Development and Evaluation of Solution Procedures for Geometrically Nonlinear Structural Analysis," AIAA Journal, 1972, Vol.10, No. 3, pp. 264-272.

[17] Haisler, W.E. and Stricklin, J.A. "Displacement Incrementation in Nonlinear Structure Analysis by the Self-correcting Method," International Journal for Numerical Methods in Engineering, 1977, Vol. 11, pp. 3-10.

[18] MSC/NASTRAN for Windows 95: McNeal-Schwendler Corporation, CA, USA, 1995. 